\title{
Leader
}

\section{Prostate cancer prevention: review of target populations, pathological biomarkers, and chemopreventive agents}

\author{
Rodolfo Montironi, Roberta Mazzucchelli, James R Marshall, Peter H Bartels
}

Arizona, Tucson,

Arizona, USA

J R Marshall

Optical Sciences

Center, University of

Arizona

P H Bartels

Correspondence to:

Professor Montironi

email:

r.montironi@popcsi.unian.it

Accepted for publication

21 April 1999

\begin{abstract}
Institute of
Pathological Anatomy

and Histopathology,

University of Ancona,

Ospedale Regionale,

60020 Torrette,

Ancona, Italy

R Montironi

R Mazzucchelli

Arizona Cancer

Center, University of

Chemoprevention is the administration of agents to prevent induction of cancer, or to inhibit or delay its progression. ${ }^{1}$ In prostatic neoplasia, the time from tumour initiation and progression to invasive carcinoma often begins in men in the fourth and fifth decades of life and extends across decades. This phenomenon represents a unique opportunity to arrest or reverse the process of carcinogenesis with the use of chemopreventive agents. For prostate cancer, as for other cancer targets, development of successful chemopreventive strategies requires suitable cohorts, reliable biomarkers for evaluating chemopreventive efficacy, and well characterised agents. ${ }^{1}$ Histopathologists have an important role in prostate chemoprevention. They define the high risk groups, recognise the surrogate end markers, and evaluate the morphological effects of the agents on the prostate tissue specimens.
\end{abstract}

\section{Target populations for prostate cancer chemoprevention}

Table 1 gives the target populations that can be considered for prostate cancer chemoprevention trials. ${ }^{2}$

\section{TARGET POPULATIONS IDENTIFIED BY} PREMALIGNANT LESIONS

High grade prostatic intraepithelial neoplasia (PIN) is the most likely precursor of invasive prostate cancer, originating from the ducts and acini, particularly those of the peripheral zone of the prostate gland. ${ }^{3}$ The histopathological continuum that culminates in early invasive adenocarcinoma is divided into two gradeslow and high-replacing the previous three grade system; PIN1 is considered low grade, and PIN2 and 3 are considered high grade. High grade PIN has several features similar to prostate cancer. ${ }^{3}$ PIN retains an intact or fragmented basal cell layer, unlike cancer, which lacks a basal cell layer. A recent consensus group determined that a small subset of basal cells houses the stem cell population. These cells are the presumptive site of origin of PIN and prostatic adenocarcinoma. ${ }^{4}$ The exact connection between PIN and prostate specific antigen (PSA) is not known, and several problems concerning their interrelation are unresolved. Research has indicated that high grade PIN alone does not account for raised serum PSA levels. ${ }^{5}$

The most common genetic alterations in PIN and prostate cancer are: the gain of chromosome 7 , particularly $7 \mathrm{q} 31$; loss of $8 \mathrm{p}$ and gain of $8 \mathrm{q}$; and loss of $10 \mathrm{q}, 16 \mathrm{q}$, and $18 \mathrm{q}$. Inactivation of tumour suppressor genes or overexpression of oncogenes in these regions may be important for the initiation and progression of prostate neoplasia. Foci of PIN and prostate cancer have a similar proportion of genetic changes, but the foci of carcinoma usually have more alterations. This supports the hypothesis that PIN is the most likely precursor of prostate cancer. $^{6-15}$

Table 1 Prostate cancer chemoprevention and chemoactive target population (from reference 2)

\begin{tabular}{|c|c|c|}
\hline Target population & Major advantage & Major disadvantage \\
\hline \multicolumn{3}{|l|}{ Chemoprevention } \\
\hline \multirow[t]{4}{*}{ 1. General population } & Findings directly applicable to general population & Requires large number of subjects \\
\hline & & Requires long study period \\
\hline & & Expensive \\
\hline & & May require biopsy at end of study to establish status \\
\hline 2. High risk groups (eg, strong family history) & $\begin{array}{l}\text { Findings directly applicable to the high risk group } \\
\text { studied }\end{array}$ & Findings may not be applicable to general population \\
\hline \multirow[t]{2}{*}{ 3. High grade PIN } & $\begin{array}{l}\text { Greatly decreases required sample size, study time, and } \\
\text { expense }\end{array}$ & $\begin{array}{l}\text { Possibility of coexisting malignancy may be decreased } \\
\text { by requiring second biopsy before randomisation }\end{array}$ \\
\hline & Easily identied on subsequent biopsies & Findings may not be applicable to general population \\
\hline \multicolumn{3}{|r|}{ 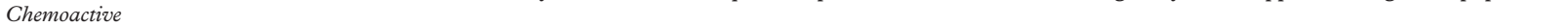 } \\
\hline $\begin{array}{l}\text { 1. Cancer on biopsy (treated during } 3 \text { to } 12 \\
\text { week period before radical prostatectomy) }\end{array}$ & Ability to evaluate whole mounted pathology specimen & $\begin{array}{l}\text { Only able to evaluate short term effects of the } \\
\text { chemopreventive agent }\end{array}$ \\
\hline \multirow[t]{3}{*}{ 2. Cancer on biopsy treated by watchful waiting } & Results would evaluate long term effects of the & Would require subsequent biopsies \\
\hline & chemopreventive agent on malignancy & Findings may not be applicable to general population \\
\hline & & $\begin{array}{l}\text { Findings may confound the heterogeneity of prostate } \\
\text { cancer }\end{array}$ \\
\hline
\end{tabular}


High grade PIN has a high predictive value as a marker for carcinoma, and its identification in biopsy specimens warrants further search for concurrent invasive cancer. High grade PIN is found in approximately $3 \%$ of biopsies. Recognising that approximately 50\% of men with high grade PIN on biopsy will be found to have carcinoma on repeat biopsy, the management of high grade PIN on biopsy may only apply to $50 \%$ of the men initially discovered with this finding. ${ }^{16}$

AFRICAN AMERICAN MEN: A TARGET POPULATION Data reported from the USA indicate that both the prevalence and the extensiveness of high grade PIN are higher in African American men than in whites, and that this discrepancy starts as early as the third decade of age. In necropsy studies by Sakr et al, ${ }^{17}$ extensive high grade PIN with diffuse involvement of the prostate gland was evident in $7 \%$ of African American men less that 50 years of age, compared with $2 \%$ of white men in the same age group. In the series of men undergoing radical prostatectomy for clinically localised prostate cancer, extensive high grade PIN was significantly and consistently higher in the African American cohort than in the white cohort. The difference was more evident in young patients and those with small, organ confined tumours. In a subset of patients with clinical stage $\mathrm{T} 1 \mathrm{c}$ prostate cancer, extensive high grade PIN was identified in 33\% of African Americans and $12 \%$ of whites. Moreover, in men with organ confined disease, both the Gleason score and the extensiveness of high grade PIN were strong predictors of biochemical recurrence. These findings suggest that an important role for high grade PIN in the development of clinically significant, potentially aggressive prostate cancer in African American men.

\section{TARGET POPULATIONS IDENTIFIED BY GENETIC} FACTORS

Recent recognition that a predisposition to prostate cancer can be inherited has led to a search for specific genes associated with the disease. Through a study of families with three or more affected first degree relatives, a region on the long arm of chromosome 1 (1q24-25) has been tentatively identified as containing a gene, HPC1, involved in the development of hereditary prostate cancer. This genetic defect on chromosome 1 occurs in one third of men with hereditary prostate cancer. This means

Table 2 Criteria for selecting intermediate biomarkers as surrogate endpoints in chemoprevention trials (from reference 1)

\footnotetext{
Fits expected biological mechanism

Differentially expressed in normal and high-risk tissue

On or closely linked to causal pathway for cancer (eg, expression increases/decreases with severity of dysplasia)

Modulated by chemopreventive agents

Latency is short compared with cance

Biomarker and assay provide acceptable sensitivity, specificity, and accuracy

Assay for biomarker is standardised and validated

Dose related response to the chemopreventive agent is observed

Statistically significant difference between levels in treatment groups and controls

Biomarker is easily measured

Biomarker can be obtained by non-invasive or relatively non-invasive techniques Assay for biomarker is not technically difficult

Biomarker modulation correlates to decreased cancer incidence

(ie, the biomarker is validated as a surrogate endpoint)
}

that approximately $30-40 \%$ of hereditary cases may be caused by this mutation. Although only about one in 500 men have this defect, it represents a significant breakthrough in the identification of genetic markers. ${ }^{18}$

Other predisposing loci have been reported. ${ }^{19}$ For instance, a close link between loss of heterozygosity at chromosome $8 \mathrm{p} 22$ and local tumour progression has been found, indicating the presence of a tumour suppressor gene at this locus. Chromosome 16q24 harbours the E-cadherin gene. Alterations in this gene seem to be involved in determining the metastatic potential of the tumour. Another predisposing factor seems to be the length of CAG repeats on the androgen receptor. Men with prostate cancer have significantly shorter repeats than age matched men with benign prostatic hyperplasia. Also Japanese men, who have a low incidence of prostate cancer, have longer CAG repeats than whites.

TARGET POPULATIONS IDENTIFIABLE BY

MOLECULAR FACTORS

Some molecular changes (such as a reduced expression of glutathione S-transferase (GST- $\pi$ ) and an enhanced expression of telomerase activity) can be detected in prostates without cancer or PIN as well as at a distance from the preneoplastic and neoplastic lesions. ${ }^{20-23}$ Such changes might be interpreted as the onset (that is, initiation stage) of the development of prostatic neoplasia. ${ }^{4}$ Under certain conditions the lesions characterised by molecular changes might be able to progress to a morphologically identifiable premalignant stage and may then, owing to severe genetic instability, result in a clone that has the ability to invade. Data related to the formation of DNA adducts in normal tissue adjacent to cancer in humans support this hypothesis. ${ }^{24} 25$ According to Han et al, ${ }^{26}$ the selective occurrence of a DNA adduct in the tissue of origin of carcinomas and preceding carcinoma development suggests a causal relation between adduct formation and prostate cancer development in testosterone plus oestradiol-17 $\beta$ treated rats.

\section{Surrogate endpoint biomarkers for clinical trials on prostate cancer chemoprevention}

Table 2 shows the criteria for selecting intermediate biomarkers as surrogate endpoints in chemoprevention trials. ${ }^{1}$ Table 3 reports the candidate surrogate endpoint biomarkers being used in chemoprevention studies on prostate cancer. ${ }^{27}{ }^{28}$ In the process of defining a surrogate endpoint biomarker (SEBM), two considerations play a role. The first concerns properties that the SEBM should have; the second relates to the phase of oncogenic progression that the SEBM is intended to monitor.

An effective SEBM should allow sensitive detection and precise characterisation of oncogenic progression. This implies that the SEBM should be an objectively measurable entitythat is, allow a numerical assessment. One may define a progression curve spanning the range from normal tissue to an infiltrating lesion. The 
Table 3 Candidate surrogate endpoint biomarkers based on structural abnormalities of $D N A$, proteins, and carbohydrates (modified from reference 28)

Class I. Nuclear/nucleolar structural abnormalities

- Nuclei: abnormal size, shape, chromatin texture, DNA ploidy

- Nucleoli: abnormal number, size, shape, position, pleomorphism

Class II. Genomic structural abnormalities

- DNA abnormalities (restriction endonuclease/gel and FISH assays)

a. Point mutation

b. Gene amplification

c. Loss of heterozygosity

- Chromosome aberrations

Micronuclei, homogeneously staining regions, double minutes, deletions, insertions, translocations, inversions, isochrosomes

- Aneuploidy

Class III. Cell proliferation and death abnormalities

PCNA, Ki-67

- Apoptotic body, others

Class IV. Oncogenes and tumor suppressor genes

- ras, p53, HER-2/neu, jun, fos, myc, abl, src, others

Class V. Altered differentiation molecules

- Fibres: actin microfilaments, intermediate fibres (keratins), microtubules

- Adhesion molecules: cell-cell (tight and gap junction, desmosomes), cell substrate (integrins, cadherins, laminins, fibronectins, collagens, proteoglycans)

- Glycoconjugates: mucins (Tn, T, sialo $\mathrm{Tn})$, blood group substances $\left(\mathrm{Le}^{\mathrm{x}}\right)$, glycolipids

Class VI. Altered growth factors/receptors

- $\operatorname{PDGF}(\mathrm{R}), \mathrm{EGF}(\mathrm{R}), \mathrm{TGF} \beta(\mathrm{R}), \mathrm{FGF}(\mathrm{R}), \mathrm{IGF}(\mathrm{R})$, others

state of a given case would be reflected by the value of a progression index indicating the case position along the progression curve. ${ }^{29}$ Efficacy of a chemopreventive intervention then would be monitored by changes in the value of the progression index. Even a small difference in progression or regression should be clearly reflected in the value of the progression index. The sampling requirements for a statistically valid detection of change must be firmly established. Tissue sampling requirements should be such that the procedure can be kept minimally invasive so that repeat biopsies are feasible.

The progression index should represent tissue characteristics that are reversible so that not only progression but also halted progression or true regression can be observed. The progression assessment should be responsivethat is, the effects of chemopreventive intervention should be reflected in the progression index after a short time. For example, tissue architectural changes concomitant with oncogenic progression - such as the disruption of the basal cell layer in PIN lesions, multiple layering of the secretory epithelium, or the assessment of number, size, and morphology of capillaries in the vicinity of PIN lesions - may take weeks or months to reflect a regressive effect. However, changes in the spatial and statistical distribution of nuclear chromatin, or microphotometric monitoring of the amounts of certain gene products by immunohistochemistry, may be expressed and measurable within days. ${ }^{29-31}$

Ideally, the micromorphometric or microphotometric characteristics entered into the value of the progression index should undergo a monotonic trend from normal tissue to infiltrating disease. If that is not possible, additional criteria must be defined so that an observed progression can unequivocally be assigned to a certain segment on the progression curve. Various micromorphometric entities have been found eminently suitable for the establishment of a progression curve for ductal carcinoma in situ of the breast $\mathrm{t}^{32}{ }^{33}$ and solar keratosis of the skin. ${ }^{34}$ In the prostate, both histometric entities - such as the degree of disruption of the basal cell layer, ${ }^{35}$ and karyometric variables, ${ }^{3637}$ again derived from the nuclear chromatin texture ${ }^{31}$ - provide a well defined progression curve for PIN lesions. Thus, for the assessment of lesion progression, suitable procedures have already been developed. ${ }^{34}$ There is, unfortunately, an almost total lack of quantitative micromorphometric studies of clinical materials from chemoprevention trials.

In chemoprevention one is usually facing a situation where tissue alterations or karyometric changes are still at the early stage of oncogenic progression, and thus are subtle. It is therefore not surprising that in a randomly sampled cell population not all cells are uniformly progressed, as was also found in the studies cited above. Rather, only a certain proportion of nuclei may show the effects of oncogenic progression. The progression index curve was therefore defined on the basis of data from the $10 \%$ most progressed nuclei classified as showing signs of actinic damage. This approach has been found to allow sensitive detection of the efficacy of chemopreventive agents. It shows these effects undiluted by the values seen in the bulk of nuclei in a cell population which did not deviate from normal in the first place.

There is a need to examine the sampling protocol carefully with respect to adequacy of sample size, representativeness for the condition of the lesion and potential local heterogeneity, and finally, for inherent biases. For example, a protocol may call for two biopsies from the centre of a lesion before and following a chemopreventive regimen. This may automatically restrict sampling to lesions that are still recognisable after intervention. Their small size and the disruption induced by biopsy make this evaluation of chemopreventive efficacy difficult for high grade PIN lesions. While it constitutes a stringent test for efficacy, the requirement may induce a bias by not considering lesions that responded to intervention.

An SEBM derived from a topographically much more widely expressed phenomenon, such as the malignancy, or PIN associated changes in the chromatin of nuclei from histologically normal appearing tissue, would not have this problem. ${ }^{31}$ Even an ultrasound guided needle biopsy may not provide a sample that directly reflects regression at the previously biopsied site. There may be effects of the disturbance of the tissue by the previous needle insertion, and one may also have to consider local grade heterogeneity, even in a small lesion.

A case can therefore be made for the need for a placebo arm in such studies. Image analytical procedures result in quantitative numerical data, and usually there would not be a need to provide a placebo arm to rule out subjectivity in the evaluation. But the above sampling problems might well not allow an unequivocal assessment of efficacy, unless compared statistically with the placebo arm results. On the other hand, chromatin texture assessment is a highly sensitive procedure, and one has to con- 
sider the potential effects induced by the placebo.

The second set of considerations relates to the events in oncogenic progression that an SEBM should monitor. Consider as a general interval of interest the range from an initiating event, at the genomic/molecular level at the beginning, and infiltrating disease with potential for metastasis at the end. One has, in the sequence of oncogenic progression, to distinguish between necessary but not sufficient events, and events that clearly form part of an inevitable, deterministic continuation to infiltrating disease. A molecular event, at the gene level, may well be a crucial initiating step towards a malignancy. Thus it may be a necessary event. But it is by no means clear, and even improbable, that every such event will inevitably result in an infiltrating lesion-in many instances it is insufficient.

On the other hand, it also is not a reversible event. A progression measure based on detection of such an event may therefore always detect its presence, even if a chemopreventive regimen had successfully halted, and possibly partially reversed, subsequent oncogenic progress. Molecular genetic probes can provide a profile revealing the set of genomic defects relating to oncogenic progression. For an individual nucleus each such marker provides definitive detection-which of course is a binary result-rather than being an index measuring continuous change.

Changes in the nuclear chromatin texture offer the advantage that they reflect a reversible phenomenon, and that they offer detection even before histopathological assessment could discern change. Chromatin changes reflect processes that occur later than the earliest initiating molecular events. They occur at a phase in oncogenic progression close to the evolution of a deterministic process and can be closely followed up to the occurrence of microinfiltration. It is not clear even now whether a point of deterministic and inevitable progression to infiltrating disease can be defined, even though numerous necessary preceding events have been identified.

Ploidy measurement presents a case in point. ${ }^{3637}$ A highly aneuploid lesion, with its obvious genomic instability, ranks high as a measure of lesion progression. A high level of aneuploidy, though, may not be very suitable as an SEBM. If lowered ploidy values in a cell population undergoing progression were taken as a marker for regression one may have difficulty in interpreting the biological basis. Does this mean that nuclei with very severe genomic instability have disappeared, for example because of enhanced induction of apoptosis? Or does it mean that a clone of lower ploidy is in the ascendancy? Such clones may, in fact, have higher potential for invasion, so that the SEBM suggests regression when in fact exactly the opposite is taking place. There are, fortunately, several micromorphometric and microphotometric entities that may make good SEBMs. The averaged deviation of chromatin texture features from normal is a useful measure. The distribution of this index among the nuclei of a lesion before and after chemopreventive intervention may lend itself well to defining an SEBM.

In the search for suitable measures of oncogenic progression an argument could be put forward for the choice of entities that manifest themselves immediately before, or during, the development of a histopathologically recognisable lesion. The phase of oncogenic progression from the initiating molecular event to the point where micromorphometric changes are detectable is still largely unexplored. It is likely that there are several pathways-possibly a substantial number-leading to progressive change, and sequential development of multiple genomic defects may play an important role. However, it is not clear at this time whether progression might not occur even without the induction of a specific genomic defect in such a sequence. Cellular metabolism, in principle, involves a complex system with numerous non-linear processes, controlled by a myriad of feedback and control mechanisms that, once disturbed, might well be subject to derailment in various different ways. Measurements monitoring tissue changes further along progression may therefore offer a safeguard for detecting progression even if a given genomic event was not observed.

\section{Drug treatment and prevention}

Several potentially chemopreventive drugs have been studied in carcinogenesis models in the prostate both in vitro and in vivo. Table 4 shows a selection of mechanisms and agents for intervention and prevention of prostate carcinogenesis. $^{38}$

HORMONAL MANIPULATIONS

Androgens are pivotal regulators of prostate growth, differentiation, and function. Their actions are believed to be involved in prostate cancer development. ${ }^{39}$ The androgen signalling pathway in the prostate gland is therefore one of the possible sites of intervention in prostate cancer prevention efforts. ${ }^{239}$ The central element of androgen signalling in the cell is the androgen receptor, a member of the superfamily of nuclear receptors. Binding of androgen to its ligand binding domain transforms the receptor to an active transcription factor that regulates gene expression by interacting with specific regulatory elements in the promoters of the genes. In addition to this genomic action, the androgen receptor also interacts with other signalling pathways through protein-protein interaction. It is not only the action of androgen hormones, but also the interactions of growth factor and protein kinase A signalling pathways, that can induce activation of androgen receptor. Moreover, these ligand dependent activators act synergistically together with low concentrations of androgens.

\section{5a-Reductase inhibition}

Finasteride acts as a competitive and specific inhibitor of $5 \alpha$-reductase, resulting in suppression of serum and intraprostatic dihydrotestosterone concentration to castrate levels, with subsequent reduction in prostatic size. $5 \alpha-$ 
Table 4 Selected mechanisms and agents for intervention and prevention of prostate carcinogenesis (from reference 38)

\begin{tabular}{|c|c|c|}
\hline Mechanism & Possible molecular targets & Potential agents \\
\hline \multirow[t]{4}{*}{ Antiandrogen/antioestrogen } & Steroid $5 \alpha$-reductase (inhibition) & Finasteride; FCE 28260; retinoids \\
\hline & Androgen receptor (antagonism) & Casodex \\
\hline & Steroid aromatase (inhibition) & Exemestane; liarozole \\
\hline & Oestrogen receptor (antagonism) & Tamoxifen; genistein \\
\hline \multirow[t]{4}{*}{ Antiangiogenesis } & FGF receptor (tyrosine kinase inhibition) & Genistein \\
\hline & TNF- $\alpha$ (inhibition) & \\
\hline & Integrins focal adhesion kinase & Linomide; thalidomide \\
\hline & Thrombomodulin (induction) & Monoclonal antibodies; peptides; retinoids \\
\hline Antimutagen & GST (enhancement) & Oltipraz \\
\hline \multirow[t]{5}{*}{ Antiproliferative } & E-Cadherin (enhancement) & E-cadherin "mimetics" \\
\hline & EGF receptor (tyrosine kinase inhibition) & PD 153035 \\
\hline & Ornithine decarboxylase (inhibition) & Difluoromethylornithine \\
\hline & Telomerase (inhibition) & "Anti-telomerase agents" \\
\hline & Nucleotide synthesis (inhibition) & Fluasterone \\
\hline $\begin{array}{l}\text { Antioxidant (antimutagen } \\
\text { and antiproliferative) }\end{array}$ & Activated oxygen (quenching) & 5'-Lipoxygenase inhibitors; selenium; vitamin E \\
\hline \multirow[t]{2}{*}{ Apoptosis induction } & TGF- $\beta$ (inhibition) & Retinoids; tamoxifen \\
\hline & ras farnesylation (inhibition) & Perillyl alcohol \\
\hline Differentiation induction & TGF- $\beta$ (induction) & Retinoids, vitamin D analogues \\
\hline $\begin{array}{l}\text { Modulation of gene } \\
\text { expression }\end{array}$ & GSTP1 (reversal of methylation) & $\begin{array}{l}\text { 5-aza-2'-deoxycytidine (cytidine methyltransferase } \\
\text { inhibition) }\end{array}$ \\
\hline
\end{tabular}

Reductase inhibition results in a significant increase in intraprostatic testosterone levels, allowing testosterone mediated functions, including libido, potency, and male musculature, to remain largely unaffected. Finasteride is approved for treatment of symptomatic benign prostatic hyperplasia. It is associated with a $50 \%$ reduction in PSA, which is significantly less than the reduction associated with medical or surgical castration. Tumour growth has been suppressed by $5 \alpha$-reductase inhibition in animal and human tumour lines. An attractive feature of finasteride is its excellent safe profile, making it a reasonable candidate for chemoprevention trials in the general and high risk target populations. ${ }^{40}$ The modest morphological changes induced by finasteride raise concern that this drug may not be sufficiently effective to prevent or reverse high grade PIN or prostate cancer.

\section{Antiandrogens}

Antiandrogens competitively bind to androgen receptors at the target cell level. This class of agents blocks testicular and adrenal androgens. Antiandrogens are currently approved for use in combination treatment with a luteinising hormone releasing hormone analogue for complete androgen blockade in the management of prostate cancer. Bicalutamide and flutamide are non-steroidal antiandrogens that selectively inhibit androgen receptors, including those in the prostatic cytoplasm. ${ }^{41}$ These agents have no androgenic or progestational activity, and are able to counteract testicular and also adrenal androgens effectively. Antiandrogens and $5 \alpha$-reductase inhibitors, if used alone or in combination to prevent or reverse high grade PIN or prostate cancer, may offer a quality of life advantage over other androgen ablation methods because they do not reduce serum testosterone and therefore do not have a marked inhibitory affect on libido and potency.

\section{Other hormonal agents}

Continuous administration of high doses of luteinising hormone releasing hormone analogues causes inhibition of luteinising and follicle stimulating hormone release with subse- quent suppression of testosterone production at the testicular level. The major side effects of these agents include impotence, loss of libido, atrophy of the reproductive organs, and hot flushes. These potent agents are not suitable for chemoprevention in the general population; however, in high risk target populations such as those with high grade PIN, perhaps three to six months of treatment could significantly improve outcome, outweighing the side effects incurred during the treatment interval.

Combining androgen ablation agents may decrease prostate cancer risk in target populations such as those with high grade PIN. Combination treatment may decrease overall side effects by lowering effective dosages and shortening treatment duration. A non-steroidal antiandrogen agent could be used in combination with a $5 \alpha$-reductase inhibitor in men who want potency preserved. Combination treatment with a luteinising hormone releasing hormone analogue and an antiandrogen would be an option for men in whom potency is not a concern.

Other than its cardiovascular complications, oestrogens have been associated with fluid retention, gynaecomastia, and loss of libido and potency, side effects that probably outweigh a chemopreventive benefit of these agents. $^{42}$

\section{RETINOIDS}

Vitamin A and its products, retinoic acid and the retinoids, are essential in the normal control of epithelial cell growth and cellular differentiation. They appear to act in a hormone-like way, targeting specific organs, of which the eye and the liver are the best documented. It has long been known that they are important for the maintenance of a normal germinal epithelium and are necessary for the differentiation of prostate glandular epithelium. ${ }^{43}$ There is interdependence between vitamin A and zinc. This is most clearly demonstrated in patients with poor dark adaptation, in which full night vision is not restored until both elements are replaced, the presence of either one alone being insufficient. 
A reciprocal relation between serum zinc and serum vitamin A in patients with prostate cancer has not been demonstrated, suggesting that this interdependence may be disrupted in such patients. There is abundant in vitro experimental evidence showing that vitamin A has a beneficial effect in preventing prostatic carcinogenesis. ${ }^{45}$ Importantly, in these experiments trans-retinoid and $\beta$ retinoid enhance normal apoptotic activity. That retinoid supplements do work effectively in restoring normal function is seen in patients with acne, the androgen dependent skin disease, when they are treated in this fashion over prolonged periods. Sufficiently large experimental studies on dietary supplementation, however, remain to be performed.

\section{VITAMIN D}

An inverse correlation between ultraviolet radiation, the principal source of vitamin $\mathrm{D}$, and prostate cancer mortality has been shown in epidemiological studies. ${ }^{46-49}$ Low serum concentrations of the active metabolite of vitamin D, 1,25-dihydroxyvitamin $\mathrm{D}_{3}\left(1,25(\mathrm{OH})_{2} \mathrm{D}_{3}\right)$, are associated with increased risk of clinical prostate cancer in older men. Genetic variations in the vitamin $\mathrm{D}$ receptor confer risk for advanced disease. $1,25(\mathrm{OH})_{2} \mathrm{D}_{3}$ binds to high affinity vitamin $\mathrm{D}$ receptor on normal and malignant human prostatic epithelial cells and elicits a variety of biological responses, including decreased proliferation and increased differentiation. ${ }^{50}$ Animal models have provided further evidence that vitamin $\mathrm{D}$ can both inhibit prostate tumour formation and slow the growth of established tumours.

In pilot clinical studies, ${ }^{51}$ some efficacy of vitamin $\mathrm{D}$ treatment has been noted. In several patients with advanced, hormonally refractive prostate cancer, serum PSA levels fell for a short period. In patients with minimal recurrent disease, tumour doubling time was increased by a mean of $45 \%$ during treatment with $1,25(\mathrm{OH})_{2} \mathrm{D}_{3}$, assessed by serum PSA values. Current research activities include identification of vitamin D analogues with less hypercalcaemic activity, the mechanism of action of vitamin $\mathrm{D}$ on prostate cells, genetic factors involved in synthesis of and response to $1,25(\mathrm{OH})_{2} \mathrm{D}_{3}$, interaction with other factors such as androgens, and models to evaluate the chemopreventive activity of vitamin D against prostate cancer.

\section{DIFLUOROMETHYLORNITHINE}

Difluoromethylornithine is a potential prostate cancer chemopreventive agent. ${ }^{52}{ }^{53}$ It thwarts cell proliferation by inhibiting polyamine synthesis. Polyamines are normal cell constituents important for cell proliferation. The enzyme ornithine decarboxylase is responsible for the first and rate limiting step in mammalian synthesis of polyamines. An increase in ornithine decarboxylase activity is thus necessary for cell proliferation. Difluoromethylornithine is a suicide substrate that inactivates ornithine decarboxylase by irreversible binding to it. $\mathrm{Di}$ fluoromethylornithine may be especially effective in the prevention of prostate cancer because the prostate has very high concentrations of polyamines and polyamine synthetic enzymes. Kadmon et al have found chemopreventive activity in Dunning R3327 rat prostatic carcinoma models. ${ }^{52}$ There are several reasons, including toxicity, that would make difficult to mount a large scale study of this agent.

\section{ANTIANGIOGENIC AGENTS}

There are two distinct phases during prostatic carcinogenesis with regard to tumour blood vessel development. ${ }^{545}$ During the first or prevascular phase, which may persist for years, cells that have undergone some but not all of the transformation steps undergo a limited amount of net growth, producing premalignant lesions such as PIN. Once this angiogenic phase is reached, new blood vessel development is greatly enhanced within the cancer. It is this enhanced tumour angiogenesis which allows these cancers both to grow continuously and to metastasise. Understanding the events controlling angiogenesis could allow the development of new therapeutic approaches to prevent neoplastic progression as well as to induce the regression of cancers and their precursors. ${ }^{54}$

Linomide $^{56}$ is a low molecular weight, water soluble agent with excellent oral absorption. Treatment with linomide has antiangiogenic abilities against a series of rat and human prostatic cancer xenografts growing in vivo. Using the Matrigel in vivo angiogenesis assay, daily oral linomide $(25 \mathrm{mg} / \mathrm{kg} / \mathrm{d})$ inhibits angiogenesis induced by tumour necrosis factor $\alpha$, acidic fibroblast growth factor, basic fibroblast growth factor, and vascular endothelial growth factor. Using an $N$-methylnitrosourea initiation-androgen promotion model, linomide was given for at least one year without major toxicity, while inhibiting the development of seminal vesicle/prostate cancer in male rats by $>50 \%$. Dose-response analysis showed that a linomide blood level of $50-100 \mu \mathrm{M}$ is optimal for such chemoprevention. In addition, linomide treatment at a dose of 25 $\mathrm{mg} / \mathrm{kg} / \mathrm{d}$ was able to inhibit by approximately $60 \%$ the incidence of $N$-methylnitrosourea induced mammary carcinogenesis in female rats, and by approximately $50 \%$ that induced by 7,12-dimethylbenz $(\alpha)$ anthracene.

\section{Diet intervention and prevention}

Epidemiological studies support the hypothesis that the composition of the diet has a potential influence on prostate carcinogenesis. Some of the factors that may make important contributions to overall prostate cancer risk are selenium, dietary fat, and phyto-oestrogens. ${ }^{57}$

\section{SELENIUM}

The nutritionally essential trace element selenium was first associated with cancer risk in the late 1960s. Since then, a substantial body of research has elucidated functions of selenium in normal metabolism and documented the cancer prevention potential of selenium supplementation in animals. Selenium compounds have been shown to have antitumorigenic activities in animal models when the drug is given at levels greater than those associated 
with nutritional needs. Several hypotheses have been proposed to explain the inhibition of tumorigenesis by supplemental selenium, including protection against oxidative damage involving the function of selenium as an essential component of the antioxidant enzyme glutathione peroxidase, alterations in carcinogen metabolism, production of cytotoxic selenium metabolites, inhibition of protein synthesis, inhibition of specific enzymes, and stimulation of apoptosis. ${ }^{585}$

Geographical studies suggest an inverse relation between selenium status and cancer incidence in humans. In a study of the ecological relation of environmental selenium levels (forage crop selenium) and county levels of cancer mortality in the USA, cancer mortality rates were significantly lower for total cancer and cancers of the lung, colon and rectum, bladder, oesophagus, pancreas, breast, ovary, and cervix in counties with intermediate selenium or high selenium levels compared with low selenium counties. A prospective study among 50000 health professionals has shown selenium to be associated with lower risk; a nested case-control study in which toenail selenium was used to assess selenium status indicated that raised selenium levels are associated with a $50 \%$ decrease in prostate cancer risk. ${ }^{60}$ Two smaller studies ${ }^{6162}$ yielded similar evidence. On the other hand, a prospective study conducted in Finland ${ }^{63}$ showed little evidence of such effects (selenium in this latter study was represented by serum concentrations).

A study of the incidence of prostate cancer has shown that selenium supplementation decreases the incidence in men with a history of non-melanoma skin cancer. ${ }^{64}$ This study, a clinical trial reported by Clark et $a l,{ }^{64}$ provides the strongest human based evidence that selenium protects against prostate cancer. That trial indicated that $200 \mu \mathrm{g} /$ day of selenium supplementation, with selenium delivered in yeast, decreases prostate cancer risk by approximately $60 \%$. However, as prostate cancer was one of several secondary endpoints considered (the study was designed to evaluate the protective impact of selenium against basal and squamous cell skin cancers within a population characterised by previous skin cancer and by residence in regions with low selenium forage levels) the finding needs to be replicated. ${ }^{57}$

DIETARY FAT

The higher amounts of dietary fat in western Europe, the USA, and Canada have been suggested to explain the higher prostate cancer mortality in these populations. ${ }^{65}$ Overall, a diet in which $40-60 \%$ of energy comes from fat appears to increase the relative risk of prostate cancer by a factor of 1.6 to 1.9 . This association appears strongest for fat from meat. ${ }^{65}$ There is evidence that a population with a lifetime pattern of low fat consumption has a lower risk of prostate cancer. To date no definitive study has been conducted to determine if a change to a low fat diet after years of a diet high in fat will lower prostate cancer risk.
The molecular mechanisms linking dietary fat to prostrate cancer biology, however, are not completely understood. Diets high in fat are associated with an increased production of sexual hormones. Black African men fed a Western diet have an increased excretion of both androgens and oestrogens, while the opposite trend was shown in African American men fed a vegetarian diet. $^{6566}$ Therefore, dietary fat is presumably converted to androgens, leading to increased androgen stimulation of the prostate. This may translate into an increased risk of hormonally induced tumours.

Animal fats are typically rich sources of arachidonic acid and this fatty acid is converted into a wide range of powerful compounds, including prostaglandins and leukotrienes. ${ }^{65} 66$ It has been shown that the PC3 and LNCaP cell lines convert arachidonic acid into the 5-lipoxygenase product, 5-hydroxyeicosatetraenoic acid (5-HETE). When the formation of 5-HETE is abolished, human prostate cancer cells enter apoptosis in a very short time, usually minutes, and are dead within two hours. Exogenous 5-HETE can prevent death of these cancer cells. These findings indicate that lipoxygenase inhibition has a role in the development of prostate neoplasia and that 5-HETE is a potent survival factor for human prostate cancer cells. ${ }^{67}$

PHYTO-OESTROGENS AND DIETS HIGH IN FRUITS AND VEGETABLES

Isoflavonoids, flavonoids, and lignans are phyto-oestrogens derived from soya, tea, fruits, and vegetables. They have been proposed as chemopreventive agents in Asian men, in whom the incidence of prostate cancer is much lower than in Western populations. ${ }^{68}$ Lower incidences have also been noted in vegetarians compared with omnivorous men. Oestrogen antagonistic activity has been described for some of these compounds, in addition to a weak oestrogenic activity. Furthermore, the lignan enterolactone and the soya derived isoflavone, genistein, are inhibitors of several steroid metabolising enzymes such as aromatase, $5 \alpha$-reductase, and $17 \alpha$-hydroxysteroid dehydrogenase. Genistein is a potent inhibitor of tyrosine kinases and, along with flavonoids such as kaempferol and apigenin, is also an inhibitor of topoisomerases I and II, enzymes that are crucial to cell proliferation. Genistein is also an inhibitor of angiogenesis. In many experimental in vivo and in vitro models, including those for cancer of the prostate, isoflavonoids, flavonoids, and lignans inhibit growth. It is estimated that the traditional Japanese diet provides a man with approximately $20 \mathrm{mg}$ of isoflavones a day, compared with less than $1 \mathrm{mg}$ a day provided by a typical Western diet. This is reflected in the high mean plasma concentration of genistein in Japanese men $(180 \mathrm{ng} / \mathrm{ml})$, compared with a level of $<10 \mathrm{ng} / \mathrm{ml}$ for Western men. ${ }^{69}{ }^{70}$ It is possible that other agents found within fruits and vegetables are protective. One large prospective study has provided evidence that lycopene, a carotenoid with substantial antioxidant activity, is associated with decreased risk of prostate 
cancer; one other study conducted in Hawaii was noteworthy for its failure to observe this effect. ${ }^{71}$ There may have been inadequate variance in lycopene intake in this population to allow for detection of protective effects.

One of the few positive outcomes of the $\alpha$ tocopherol $\beta$ carotene chemoprevention trial, conducted among some 29000 heavy smokers in Finland, was a 30\% reduction in prostate cancer incidence by $\alpha$ tocopherol or vitamin E. ${ }^{6372}$ This reduction was statistically significant and a reduction of this magnitude would be clinically significant as well. ${ }^{72}$ This finding needs to be tested in another large clinical trial, as it was an unanticipated consequence of the trial.

\section{Animal models in defining efficacy of chemoprevention agents against prostate cancer}

Detection of inhibitory effects on de novo prostate cancer development requires a high cancer incidence and similarity of induced tumours to human prostate carcinomas. The following animal models have produced high incidences of multifocal prostate adenocarcinoma: transgenic mice with oncogenes expressed in a prostate specific fashion; Noble rats that have been treated chronically with combination of $17 \beta$-oestradiol and testosterone; and Wistar or F344 rats treated sequentially with a single injection of $\mathrm{N}$-methyl$N$-nitrosourea (MNU) and chronic administration of testosterone. PIN most often occurs in the first two models, and metastases are frequent in some transgenic models and the MNU-testosterone model. ${ }^{47}{ }^{73-76}$

The chemopreventive efficacy of a series of agents using a model in which hormone dependent prostate cancer is induced in the Wistar-Unilever rat. $^{77}$ This is achieved by sequential treatment with an antiandrogen (cyproterone acetate), and androgen (testosterone propionate) and a direct acting chemical carcinogen ( $N$-methyl- $N$-nitrosourea), followed by chronic androgen stimulation (testosterone). This regimen reproducibly induces a high incidence $(<75 \%)$ of prostate cancer, with no gross toxicity and a low incidence of neoplasia in the seminal vesicles and other non-target tissue. Dehydroepiandrosterone (DHEA) and 9-cis-retinoic acid (9-cis-RA) are the most active chemopreventive agents identified to date. DHEA inhibits the induction of prostate cancer when administration is started before carcinogen exposure, and when it is delayed until incipient neoplastic lesions are present. Chronic administration of 9-cis-RA starting before carcinogen exposure is highly effective in the chemoprevention of prostate cancer. Liarozole fumarate confers modest protection against induction of prostate cancer, whereas $\mathrm{N}$-(4-hydroxyphenyl)retinamide (4HPR), $\alpha$-difluoromethylornithine, DL- $\alpha$ tocopherol acetate (vitamin E), oltipraz, and L-selenomethionine are inactive. The differential activity of 9-cis-RA and 4-HPR suggests the ligand specificity may be a determinant of retinoid action in prostate cancer chemoprevention.
The effects of long term androgen deprivation on androgen signalling have been investigated in the LNCaP cell culture system. ${ }^{78}$ Long term culture in a steroid-free medium results in a subline showing a hyperreactive androgen receptor characterised by increased androgen receptor expression and enhanced androgen receptor transcriptional activity in an environment with low levels of androgen hormones. It is not yet clear if similar changes also occur in normal or premalignant prostate epithelial cells and are thus relevant for prevention trials assessing interference with androgen hormone signalling.

\section{Chemoprevention strategies}

The most efficient strategy for developing a chemoprevention programme is to perform two clinical trails concurrently, each based on the modulation of high grade PIN but in different target populations. ${ }^{38} 57$

In patients with high grade PIN associated with prostate cancer, a prospective, double blind, placebo controlled chemoactive pilot study designed to measure the response of a potential chemopreventive agent in the period (three to six weeks) before radical prostatectomy could easily be performed. Androgen deprivation treatment is commonly used in this population to downsize the prostate before radical prostatectomy. This study may provide information regarding the effectiveness of proposed agents on surrogate endpoint biomarkers, premalignant lesions, and cancer. In particular, such an investigation would determine the response of PIN to the agent in whole mounted radical prostatectomy specimens. In some preliminary investigations it has been shown that there is a marked decrease in the prevalence and extent of PIN in prostates after androgen deprivation treatment, as compared with untreated prostates. ${ }^{79}$ This is accompanied by regressive changes in the secretory epithelium. Apoptotic bodies are more often seen in the treated normal prostate, PIN, and prostate cancer than in untreated cases. This suggests that androgen ablation induces epithelial regression by enhancing apoptosis. The low proliferating cell nuclear antigen (PCNA) and Ki67 related values and the absence of mitoses in PIN as well as in normal prostate and prostate cancer in the treated cases indicates suppressed proliferation activity as a consequence of androgen deprivation treatment. ${ }^{118081}$ It has be reported that angiogenesis is inhibited in prostate lesions when total androgen ablation induces cell regression and activation of the apoptosis type of cell death. ${ }^{54}$ Consequently, the epithelial cells are blocked from expressing, producing, or exporting angiogenic molecules. All these findings indicate that the dysplastic prostatic epithelium is hormone dependent.

A short term prospective, double blind, placed controlled phase II chemopreventive trial with cancer as an endpoint could be done in patients with high grade PIN without cancer. Chemoprevention trials designed to reverse high grade PIN may be confounded by the presence of underlying but undetected 
Table 5 National Cancer Institute Chemoprevention Branch: sponsored or funded phase II/III clinical chemoprevention trials: prostate cancer (from reference 82)

\begin{tabular}{|c|c|c|}
\hline Agent & Cohort (treatment period) & Primary endpoints \\
\hline \multicolumn{3}{|l|}{ Phase II } \\
\hline \multirow[t]{3}{*}{ DFMO } & Scheduled for prostate cancer surgery ( $4-8$ weeks) & $\begin{array}{l}\text { Histopathology (PIN grade, nuclear polymorphism, nucleolar } \\
\text { polymorphism, ploidy), proliferation biomarkers (PCNA, Ki-67) }\end{array}$ \\
\hline & $\begin{array}{l}\text { Scheduled for prostatectomy (stage A or B prostatic carcinoma or } \\
\text { bladder cancer without prostatic carcinoma and scheduled for } \\
\text { cystoprostatectomy) (14 days) }\end{array}$ & $\begin{array}{l}\text { Drug effect measurements: ODC activity (skin and prostate), polyamine } \\
\text { levels (prostate). Histopathology (TRUS guided biopsies). } \\
\text { Biochemical biomarkers: PSA, PAP, testosterone }\end{array}$ \\
\hline & $\begin{array}{l}\text { Serum PSA } 3-10 \mathrm{ng} / \mathrm{ml} \text { (includes patients with prostatic } \\
\text { carcinoma and PIN) (14 days-1 year) }\end{array}$ & $\begin{array}{l}\text { Drug effect measurements: ODC activity (skin and prostate) Polyamine } \\
\text { levels (prostate). Histopathology (TRUS-guided biopsies) Biochemical } \\
\text { biomarkers: PSA, PAP, testosterone }\end{array}$ \\
\hline DHEA & Scheduled for prostate cancer surgery ( 28 days) & $\begin{array}{l}\text { Histopathology (PIN grade, nuclear polymorphism, nucleolar } \\
\text { polymorphism, ploidy). Proliferation biomarkers (PCNA, Ki-67). } \\
\text { Genetic/regulatory biomarkers (p53, } b c 1-2 \text {, pc-1, chromosome 8p loss) }\end{array}$ \\
\hline Flutamide & Patients with high grade PIN (12 months) & $\begin{array}{l}\text { PIN grade and incidence, cancer incidence, nuclear polymorphism, } \\
\text { nucleolar size, ploidy. Other endpoints: PCNA, angiogenesis, } \\
\text { apoptosis, LOH chromosome 8; growth factors, PSA }\end{array}$ \\
\hline \multirow[t]{3}{*}{ 4-HPR } & $\begin{array}{l}\text { Biopsy proven non-metastatic prostate adenocarcinoma, } \\
\text { scheduled for radical prostatectomy ( } 4 \text { weeks) }\end{array}$ & $\begin{array}{l}\text { Genetic/regulatory biomarkers: TGF } \beta \text {, c-myc, p53, plasminogen } \\
\text { activators (tPA, uPA), apoptosis }\end{array}$ \\
\hline & Scheduled for prostate cancer surgery ( $4-8$ weeks) & $\begin{array}{l}\text { Histopathology: PIN grade, nuclear polymorphism, nucleolar } \\
\text { polymorphism, ploidy. Proliferation biomarkers: PCNA, Ki-67. }\end{array}$ \\
\hline & & $\begin{array}{l}\text { Differentiation biomarkers: Lewis }{ }^{\mathrm{Y}} \text { antigen. Genetic/regulatory } \\
\text { biomarkers: p53, EGFR, TGF } \alpha\end{array}$ \\
\hline \multicolumn{3}{|r|}{ 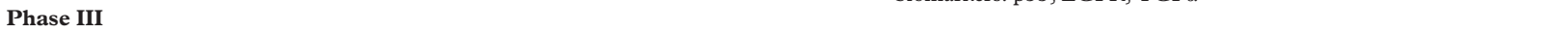 } \\
\hline Finasteride & $\begin{array}{l}\text { Men } \geqslant 55 \text { years of age with normal DRE and PSA }<3.0 \mathrm{ng} / \mathrm{ml} \\
(7 \text { years })\end{array}$ & $\begin{array}{l}\text { Prostate cancer incidence (grade and stage), BPH incidence and severity, } \\
\text { overall and prostate-specific mortality, TURP, PSA levels }\end{array}$ \\
\hline Selenised yeast & $\begin{array}{l}\text { Skin cancer (melanoma, non-melanoma) patients, low Se areas in } \\
\text { USA }(\sim 1 \text { year) }\end{array}$ & PSA levels \\
\hline
\end{tabular}

BPH, benign prostatic hypertrophy; DFMO, difluoromethyllornithine; DHEA, dehydroepiandrosterone; DRE, digital rectal examination; EGFR, epidermal growth factor receptor; PAP, prostatic acid phosphatase; PCNA, proliferating cell nuclear antigen; PIN, prostatic intraepithelial neoplasia; PSA, prostate specific antigen; Se, selenium; TGF, transforming growth factor; TRUS, transrectal ultrasound; TURP, transurethral resection of the prostate; 4-HPR,

$\mathrm{N}$-(4-hydroxyphenyl)retinamide.

prostate cancer. This difficult problem is addressed by requiring a second biopsy with negative findings for cancer before entry into the study (preferably sextant biopsies with special attention to areas of abnormality on ultrasonogram or digital rectal examination), and by including enough subjects in the study and control groups to equalise the risk of coexistent cancer between the two groups. PIN is routinely monitored by repeat biopsy in contemporary urological practice. Periodic re-evaluation would be necessary, including physical examination, rebiopsy, and evaluation of surrogate intermediate endpoint biomarkers. If subsequent biopsy reveals prostate cancer, these patients need definitive treatment. Those with PIN or no malignancy need continued observation. ${ }^{38}$

\section{Examples of clinical chemoprevention studies}

Table 5 reports agents, the treatment periods, and the primary endpoints used in clinical chemoprevention studies sponsored or funded by the National Cancer Institute. ${ }^{82}$

TRIAL OF SELENIUM AMONG HIGH GRADE PIN PATIENTS

A promising and efficient option for testing selenium is to evaluate it in a chemoprevention trial focused on a population at high risk of prostate cancer. ${ }^{83}$ Men with high grade PIN clearly comprise such a population..$^{57-85}$ The three year incidence of prostate cancer among men with high grade PIN has been estimated to be as high as $50 \%{ }^{84-86}$; men with high grade PIN are clearly appropriate subjects for prostate cancer prevention trials.

A randomised placebo controlled trial of selenium for chemoprevention of prostate cancer among men diagnosed with high grade PIN would be scientifically attractive and cost efficient. Selenium is low in toxicity at a dose of $200 \mu \mathrm{g} /$ day. In Clark's chemoprevention trial, no instances of serious toxicity were noted. ${ }^{64}$ After initial biopsy identifying high grade PIN, it will be necessary to rebiopsy before randomisation to lessen the probability that the subject has prostate cancer missed by the first biopsy. ${ }^{57}$ 83-86 The primary study outcome should be progression of high grade PIN to prostate cancer. Secondary endpoints of proliferation and apoptosis, and changes in ductal, glandular, cellular, and nuclear morphometry - including nuclear and nucleolar area, DNA content, and chromatin pattern and distribution ${ }^{29-31}$ — will also be informative and useful.

The University of Arizona, working with the Southwest Oncology Group, has embarked upon a chemoprevention trial with a placebo controlled, double blinded design, comparing $200 \mu \mathrm{g}$ selenium as 1-selenomethionine with placebo. Each participant will be treated for up to three years. The final prostate biopsy will be conducted at 36 months. The target sample size is 470 randomised patients, 235 per arm, which will require initially enrolling 1125 patients. The power will be 0.90 , with an $\alpha$ level of 0.05 , two sided, to detect a one third reduction in the three year incidence rate of prostate cancer.

Side effect differences will be monitored throughout the study. Power with even 100 patients randomised exceeds $90 \%$ to detect a difference in side effect rates of 15 percentage points if the placebo rate is around $5 \%$ and 20 percentage points if the placebo rate is in the $10-20 \%$ range, assuming 100 patients on selenium and 100 on placebo. As much larger numbers of patients will be under observation as the study progresses, sensitivity to side effects will be even greater. The primary outcome variable - three year prostate cancer 
1. Premalignant lesions, such as high grade prostatic intraepithelial neoplasia, identify patients at high risk for development of prostatic carcinoma, and these are ideal target populations for chemopreventive trials ${ }^{57}$

2 . Because of the long time period for the process of carcinogenesis and large cohort required for an evaluable study, cancer incidence is not usually a feasible endpoint for chemoprevention clinical studies. Thus identification and characterisation of intermediate biomarkers and their validation as surrogate endpoints for cancer incidence in clinical chemoprevention trials are significant components in the development of chemoprevention strategies.

3. Animal models are crucial in testing the preclinical efficacy of chemoprevention agents. ${ }^{88}$ Several animal models are used for the detection of chemo-inhibitory effects in various stages of prostate cancer development. Human prostate cancer xenografts in immunocompromised mice and transplantable rodent prostate carcinomas (ie, the Dunning rat tumour lines) can be used to assess inhibition of tumour growth. ${ }^{89}$

4. Chemoprevention trials usually use natural or synthetic agents at doses that have minimal, if any, adverse effects. However, these trials may have different acceptable toxicity tolerance levels according to the agent under investigation and the relative risk of cancer in the study population.

incidence rate-will be analysed using standard statistical techniques for dichotomous variables.

PROSTATE CANCER PREVENTION TRIAL

The National Cancer Institute and several of its cooperative oncology groups are sponsoring a randomised, double blind, placebo controlled trial to determine of $5 \alpha$-reductase inhibition will reduce the incidence of prostate cancer (phase III trial of finasteride). ${ }^{87}$ The primary endpoint is prostate cancer as determined by biopsy, and the study has a $92 \%$ power to detect a $25 \%$ difference between the finasteride and placebo arms. The prostate cancer prevention trial (PCPT) opened for participant enrolment in October 1994. Exactly three years later, the study met its enrolment goal: 18882 men aged over 55 years, with normal digital rectal examination and serum PSA concentrations of $\leqslant 3.0 \mathrm{ng} / \mathrm{ml}$, were randomised to take finasteride ( $5 \mathrm{mg} /$ day) or placebo (1 tablet/ day). Digital rectal examination and PSA were done yearly. When digital rectal examination is abnormal or PSA rises to $>4.0 \mathrm{ng} / \mathrm{ml}$, a biopsy is recommended. Because of the effect finasteride has on PSA, the PSA value has been indexed to equalise the number of biopsies in both arms. At seven years all survivors will undergo a sextant biopsy to determine the period prevalence of prostate cancer. This 10 year study will achieve its primary endpoint in 2004. A multidisciplinary group of PCPT investigators is currently focusing upon methods to maintain adherence of all study participants over the course of the next seven years of study. As the majority of prostate cancer diagnoses are expected during the final year of the study, no interim analyses are planned.

\section{Conclusions}

Chemoprevention is most effective in the early stages of cancer formation when reversibility may be feasible. ${ }^{82}$ In particular, for prostate cancer, as for other cancer targets, development of successful chemopreventive strategies requires suitable cohorts, reliable biomarkers for evaluating chemopreventive efficacy, and well characterised agents (table 6).

1 Kelloff GJ, Boone CW, Crowell JA, et al. Surrogate endpoint biomarkers for phase II cancer chemoprevention trials. $\mathcal{F}$ Cell Biochem 1994;19(suppl):1-9.

2 Karp JE, Chiarodo A, Brawley O, et al. Prostate cancer prevention: investigational approaches and opportunities. prevention: investigational a

3 Bostwick DG. High grade prostatic intraepithelial neoplasia. The most likely precursor of prostate cancer. Cancer 1995;75:1823-36.
4 Montironi R, Schulman CC. Precursor of prostatic cancer: progression, regression and chemoprevention. Eur Urol 1996;30:133-7.

5 Crawsford ED, DeAntoni EP, Ross CA. The role of prostate-specific antigen in the chemoprevention of prostate cancer. F Cell Biochem 1996;25(suppl):149-55.

6 Alers JC, Krijtenberg PJ, Vissers KJ, et al. Interphase cytogenetics of prostatic adenocarcinoma and precursor lesions: analysis of 25 radical prostatectomies in 17 adjacent prostatic intraepithelial neoplasias. Genes Chromosomes Cancer 1995;12:241-50.

7 Bergerheim USR, Kunimi K, Collins VP, et al. Deletion mapping of chromosomes 8,10 , and 16 in human prostatic carcinoma. Genes Chromosomes Cancer 1991;3:215-20.

8 Bova GS, Carter BS, Bussemakers MJG, et al. Homozygous deletion and frequent allelic loss of chromosome $8 \mathrm{p} 22$ loci in human prostate cancer. Cancer Res 1993;53:3869-73.

9 Cunningham JM, Shan A, Wick MJ, et al. Allelic imbalance and microsatellite instability in prostatic adenocarcinoma. Cancer Res 1996;56:4475-82.

10 Emmert-Buck MR, Vocke CD, Pozzati RO, et al. Allelic loss on chromosome $8 \mathrm{p} 12-21$ in microdissected prostatic intraepithelial neoplasia (PIN). Cancer Res 1995;55:295962 .

11 MacGrogan D, Levy A, Bostwick D, et al. Loss of chromosome 8p loci in prostate cancer: mapping by quantitative
allelic balance. Genes Chromosomes Cancer 1994;10:151-9.

12 Qian J, Bostwick DG, Takahashi S, et al. Chromosomal anomalies in prostatic intraepithelial neoplasia and carcinoma detected by fluorescence in situ hybridization. Cancer Res 1995;55:5408-14.

13 Qian J, Jenkins RB, Bostwick DG. Potential markers of aggressiveness in prostatic intraepithelial neoplasia detected by fluorescence in situ hybridization. Eur Urol 1996; 30:177-84.

14 Sakr WA, Macoska JA, Benson P, et al. Allelic loss in locally metastatic, multisampled prostate cancer. Cancer Res 1994; 54:3273-7.

15 Takahashi S, Qian J, Brown JA, et al. Potential markers of prostate cancer aggressiveness detected by fluorescence in situ hybridization in needle biopsies. Cancer Res 1994;54: 3574-9.

16 Will ML, Hamper UM, Partin AW, et al. Incidence of highgrade prostatic intraepithelial neoplasia in sextant needle biopsy specimens. Urology 1997;49:367-73.

17 Sakr WA, Grignon DJ, Haas GP, et al. Age and racial distribution of prostatic intraepithelial neoplasia. Eur Urol 1996; 30:138-44.

18 Smith JR, Carpten J, Kallioniemi O, et al. Major susceptibility locus for prostate cancer on chromosome 1 revealed by a genome-wide search. Science 1996;274:1371-4.

19 Isaacs WB, Bova GS, Morton RA, et al. Molecular genetics and chromosomal alterations in prostate cancer. Cancer 1995;75:2004-12.

20 Brooks JD, Weistein M, Lin X, et al. CG island methylation changes near the GSTP1 gene in prostatic intraepithelial neoplasia. Cancer Epidemiol Biomarkers Prev 1998;7:531-6.

$21 \mathrm{Kim}$ NW, Piatyszek MA, Prose KR, et al. Specific association of human telomerase activity with immortal cell and cancer. Science 1994;266:2011-15.

22 Rhyu MS. Telomeres, telomerase and immortality. 7 Natl Cancer Inst 1995;87:884-94.

23 Scates DK, Muir GH, Venitt S, et al. Detection of telomerase activity in human prostate: a diagnostic marker for prostatic cancer? Br f Urol 1997;80:263-8.

24 De Waziers I. DNA adduct in normal tissue adjacent to colon cancer [abstract]. Cancer Detect Prev 1998;22 (suppl 1): $134 \mathrm{~A}$

25 Lieberman R, Crowell JA, Hawk ET, et al. Development of new cancer chemoprevention agents: role of pharmacokinetic/pharmacodynamic and intermediate endpoint biomarker monitoring. Clin Chem 1998;44:420-7.

26 Han X, Liehr JG, Bosland MC. Induction of a DNA adduct detectable by ${ }^{32} \mathrm{P}$-postlabelling in the dorsolateral prostate of NBL/Cr rats treated with estradiol-17 beta and testosterone. Carcinogenesis 1995;16:951-4.

27 Boone CW, Kelloff GJ. Biomarker end-points in cancer chemoprevention trial. IARC Sci Publ 1997;142:273-80.

28 Boone CW, Kelloff GJ. Development of surrogate endpoint biomarkers for clinical trials of cancer chemopreventive agents: relationships to fundamental properties of preinvasive (intraepithelial) neoplasia. If Cell Biochem 1994; 19(suppl): $10-22$. 
29 Bartels PH, Montironi R, Thompson D, et al. Statistical histometry of the basal cell/secretory cell bilayer in prostatic intraepithelial neoplasia. Anal Quant Cytol Histol 1998;20. $381-8$.

30 Bartels PH, Bartels HG, Montironi R, et al. Machine vision in the detection of prostate lesions in histologic sections. Anal Quant Cytol Histol 1998;20:358-64.

31 Bartels PH, Da Silva VD, Montironi R, et al. Chromatin texture signatures in nuclei from prostate lesions. Anal Quant Cytol Histol 1998;20:407-16.

32 Bacus S, Chin D, Steward J, et al. Potential use of image analysis for the evaluation of cellular predicting factors for therapeutic response in breast cancers. Anal Quant Cyto Histol 1997; 19:316-28.

33 Mariuzzi GM, Mariuzzi L, Mombello A, et al. Quantitative study of ductal breast cancer progression. A progression study of ductal breast cancer progression. A progression index (PI) for premalignant lesion
Pathol Res Pract 1996;192:428-36.

34 Bozzo PD, Vaught L, Alberts DS, et al. Nuclear morphometry in solar keratosis. Anal Quant Cytol Histol 1998;20:218.

35 Montironi R, Bartels PH, Thompson D, et al. Prostatic intraepithelial neoplasia: quantitation of the basal cell layer with machine vision system. Pathol Res Pract 1995;191: 917-23.

36 Montironi R, Scarpelli M, Sisti S, et al. Quantitative analysis of prostatic intra-epithelial neoplasia on tissue sections. Anal Ouant Cytol Histol 1990;12:366-72.

37 Petein M, Michel P, Van Velthoven R, et al. Morphonuclear relationship between prostatic intraepithelial neoplasia and
cancers as assessed by digital cell image analysis. Am f Clin cancers as assessed by digit
Pathol 1991;96:628-34.

38 Bostwick DG. Phase II efficacy trials for chemoprevention in patients with PIN: strategies with androgen deprivation therapy. In: Crawford ED, ed. Proceedings of 7 th International Prostate Cancer Update. Beaver Creek, Colorado, 22?26 January 1997:485-90.

39 Klocker H, Culig Z, Kaspar F, et al. Androgen signal transduction and prostatic carcinoma. World F Urol 1994;12:99103 .

40 Gormley GJ. Chemoprevention strategies for prostate cancer: the role of 5á?reductase inhibitors. 7 Cell Biochem 1992;16(suppl): 113-17.

41 Civantos F, Soloway MS, Pinto JE. Histopathological effects of androgen deprivation in prostate cancer. Semin Urol on androgen deprivation in p $1996 ; 14$ (suppl 2):22-31.

42 Kirschnbaum A. Management of hormonal treatment effects. Cancer 1995;75:1983-6.

43 Peehl DM, Wong ST, Stamey TA. Vitamin A regulates proliferation and differentiation of human prostatic epithelia cell. Prostate 1993;23:69-78

44 Pienta KJ, Nguyen NM, Lehr JE. Treatment of prostate cancer in the rat with the synthetic retinoid fenretinide. Cancer Res 1993;53:224-6.

45 Young CY, Murtha PE, Andrews PE, et al. Antagonism of androgen action in prostate tumor cell by retinoic acid. Prostate 1994;25:39-45.

46 Feldman D, Skowroski RJ, Peehl DM. Vitamin D and prostate cancer. Adv Exp Med Biol 1995;375:53-63.

47 Ingles SA, Ross RK, Yu MC, et al. Association of prostate cancer risk with genetic polymorphisms in vitamin D receptor and androgen receptor. J Natl Cancer Inst 1997;89:166-70.

48 Peehl DM, Skowroski RJ, Leung GK, et al. Antiproliferative effects of 1,25-dihydroxyvitamin D3 on primary cultures of human prostatic cell. Cancer Res 1994;54:805-10.

49 Schwartz GG, Oeler TA, Uskokovic MR, et al. Human prostate cancer cell: inhibition of proliferation by vitamin D analogs. Anticancer Res 1994;14:1077-81.

50 Hedlund T, Moffatt K, Uskokovic M, et al. Three synthetic vitamin $\mathrm{D}$ analogues induce prostate-specific acid phosphatase and prostate-specific antigen while inhibiting the phatase and prostate-specific antigen while inhibiting the receptor-dependent fashion. Clin Cancer Res 1997;3:1331-

51 Peehl DM. Vitamin D and prostate cancer risk. In: Schulman C, Kelloff G, eds. Proceedings of the International Symposium "Strategies for the chemoprevention of prostate cancer". Brussels, 30-31 October 1998:19.

52 Kadmon D. Chemoprevention in prostate cancer: the role of difluoromethyllornithine (DFMO). F Cell Biochem 1992; 16(suppl): 122-7.

53 Love RR, Carbone PP, Verma AK, et al. Randomized phase I chemoprevention dose-seeking study of alphadifluoromethylornithine. $\mathcal{F}$ Natl Cancer Inst 1993;85:732-7.

54 Montironi R, Diamanti L, Thompson D, et al. Analysis of the capillary architecture in the precursors of prostate cancer: recent findi

55 Siegal JA, Yu E, Brawer MK. Topography of neovascularity in human prostate carcinoma. Cancer 1995;75:2545-51.

56 Joseph IB, Vukanovic J, Isaacs JT. Antiangiogenic treatmen with linomide as chemoprevention for prostate, seminal vesicle, and breast carcinogenesis in rodents. Cancer Res 1996;56:3404-8.

57 Nelson PS, Gleason TP, Brawer MK. Chemoprevention for prostatic intraepithelial neoplasia. Eur Urol 1996;30:26978.

58 Burk RF, Hill KE. Regulation of selenoproteins. Anпи Rer Nutr 1993;13:65-81.

59 Lanfear J, Fleming J, Wu L, et al. The selenium metabolite selenodiglutathione induces p 53 and apoptosis. Carcinogenesis 1994;15:1378-92.
60 Yoshizawa K, Willett WC, Morris SJ, et al. Study of prediagostic selenium level in toenails and the risk of advanced prostate cancer. $\mathcal{F}$ Natl Cancer Inst 1998:90:1219-24.

61 Coates RJ, Weiss NS, Daling JR, et al. Serum levels of selenium and retinol and the subsequent risk of cancer. $A m \mathcal{F}$ Epidemiol 1988;128:515-23.

62 Willett WC, Polk BF, Morris JS, et al. Prediagnostic serum selenium and risk of cancer. Lancet 1983;ii:130-4.

63 Knekt P, Aromaa A, Maatela J, et al. Serum selenium and subsequent risk of cancer among Finnish men and women. 7 Natl Cancer Inst 1990;82:864-8.

64 Clark LC, Combs GF, Turnbull BW, et al. Effects of selenium supplementation for cancer prevention in patients with carcinoma of the skin. $7 A M A$ 1996;276:1957-63.

65 Giovannucci E, Rimm EB, Colditz GA, et al. A prospective study of dietary fat and risk of prostate cancer. $\mathcal{F}$ Natl Can-

66 Morton MS, Griffiths K, Blacklock N. The preventive role of diet in prostatic disease. Br F Urol 1996;77:481-93.

67 Myers CE. Lipoxygenase inhibition in prostate cancer. In: Schulman C, Kelloff G, eds. Proceedings of the International Symposium "Strategies for the chemoprevention of prostate cancer". Brussels, 30-31 October 1998:20.

68 Fotsis T, Pepper M, Adlercreutz H, et al. Genistein, a dietary-derived inhibitor of in vitro angiogenesis. Proc Natl Acad Sci USA 1993;90:2690-4.

69 Adlercreutz H, Markkanen H, Watanabe S. Plasma concentrations of phytooestrogens in Japanese men. Lancet 1993; 342:1209-10.

70 Ross RK, Bernstein L, Lobo RA, et al. 5- $\alpha$-Reductase activity and risk of prostate cancer among Japanese and US white and black males. Lancet 1992.339:887-9.

71 Giovannucci E, Ascherio A, Rimm EB, et al. Intake of caroenoids and retinol in relationship to risk of prostate cancer. J Natl Cancer Inst 1995;87:1765-?76.

72 The Alpha-Tocopherol, Beta-Carotene Cancer Prevention Study Group. The effect of vitamin $\mathrm{E}$ and $\beta$-carotene on the incidence of lung cancer and other cancers in male smokers. N Engl f Med 1994;330:1029-35.

73 Kadomatsu K, Anzano MA, Slayter MV, et al. Expression of sulfated glycoprotein 2 is associated with carcinogenesis induced by $N$-nitroso- $M$-methylurea in rat prostate and seminal vesicle. Cancer Res 1993;53:1480-3.

74 Pollard $M$. The Lobund-Wistar rat model of prostate cancer. $\mathcal{F}$ Cell Biochem 1992;16(suppl):84-8.

75 Shirai T, Yamamoto A, Iwasaki S, et al. Induction of invasive carcinomas of the seminal vesicles and coagulating glands of F344 rats by administration of $N$-methylnitrosourea or $\mathrm{N}$-nitroso-bis (2-oxypropyl) amine and followed by testosterone propionate with or without high-fat diet. Carcinogenesis 1991;12:2169-73.

76 Slayter MV, Anzano MA, Kadomatzu K, et al. Histogenesis of induced prostate and seminal vesicle carcinoma in Lobund-Wistar rats: a system for histological scoring and grading. Cancer Res 1994;54:1440-5.

77 McCormick DL. Chemoprevention of hormone-dependent prostate cancer in the Wistar-Unilever rat. In: Schulman C, Kelloff G, eds. Proceedings of the International Symposium "Strategies for the chemoprevention of prostate cancer". Brussels, 30-31 October 1998:38.

78 Kokontis J, Takakura K, Hay N, et al. Increased androgen receptor activity and altered c-myc expression in prostate cancer cells after long-term androgen deprivation. Cancer Res 1994;54:1566-73.

79 Ferguson J, Zincke H, Ellison E, et al. Decrease of prostatic intraepithelial neoplasia (PIN) following androgen deprivation therapy in patients with stage $\mathrm{T} 3$ carcinoma treated by radical prostatectomy. Urology $1994 ; 44: 91-5$.

80 Armas OA, Melamed A, Aprikian A, et al. Effect of preoperative androgen deprivation therapy in prostatic carcinoma [abstract]. Lab Invest 1993;68:55A.

81 Montironi R, Magi Galluzzi C, Scarpelli M, et al. Quantitative characterization of the frequency and location of cell tive characterization of the frequency and location of cell
proliferation and death in prostate pathology. $\mathcal{7}$ Cell Biochem 1994;19(suppl):238-45.

82 Kellof GJ. Chemoprevention strategies for prostate cancer. In: Crawford ED, ed. Proceedings of 7 th International Prostate Cancer Update. Beaver Creek, Colorado, 22-26 January 1997:134-5.

83 Kelloff GJ, Hawk ET, Crowell JA, et al. Strategies for identification and clinical evaluation of promising chemoprevention agents. Oncology 1996;10:1471-?81.

84 Davidson D, Bostwich DG, Qian J, et al. Prostatic intraepithelial neoplasia is a risk factor for adenocarcinoma: predictive accuracy in needle biopsies. F Urol 1995;154: 1295-9.

85 Weinstein $\mathrm{MH}$, Epstein JI. Significance of high-grade prostatic intraepithelial neoplasia on needle biopsy. Hum Pathol 1993;24:624-9.

86 Bostwick DG. Target populations and strategies for chemoprevention trials of prostate cancer. $\mathcal{F}$ Cell Biochem 1994;19(suppl):191-6.

87 Thompson IA, Coltman CA, Crowley J. Chemoprevention of prostate cancer: the Prostate Cancer Prevention Trial. Prostate 1997;33:217-21

88 Leav I, Ho SM, Ofner P, et al. Biochemical alterations in sex hormone-induced hyperplasia and dysplasia of the dorsolateral prostates of Noble rats. $\mathcal{F}$ Natl Cancer Inst 1988;80: 1045-53.

89 Ellis WJ, Isaacs JT. Effectiveness of complete versus partial androgen withdrawal therapy for the treatment of prostatic cancer as studied in the Dunning R-3327 system of rat prostatic carcinoma. Cancer Res 1985;45:6041-50. 